\title{
Reasoning about definiteness in a language without articles*
}

\author{
James N. Collins \\ Stanford University
}

\begin{abstract}
Most theories of implicature make reference to a notion of alternatives. Interlocutors reason about what the speaker could have said. In this paper, I investigate the structure of these alternatives. In particular, I ask how these alternative utterances are constrained by the interlocutors' grammar. I argue that in order to derive certain implicatures, alternative utterances must be analyzed like actual utterances, as fully compositional structures appropriately generated by the grammar. The data supporting this position come from implicatures generated by indefinite bare noun phrases in Tagalog. I show that Tagalog indefinites give rise to nonuniqueness implicatures via competition with definites, as in English. However, unlike English, definite and indefinite interpretations of Tagalog NPs are not signalled by dedicated articles, but by verbal affixes. Therefore, in order to generate the observed implicatures, pragmatic competition must take into consideration the NP's broader syntactic context. Supporting the view that implicature calculation is sensitive to the morphosyntactic structure of alternative utterances, I show that in cases where the alternative is not grammatically well-formed, the implicature does not arise. These data provide evidence that only grammatically well-formed structures are able to enter into pragmatic competition.
\end{abstract}

Keywords: definiteness, pragmatic alternatives, implicatures, Maximize Presupposition, Tagalog

\section{Introduction}

Implicatures are inferences derived jointly by interlocutors, reasoning about a speaker's utterance as well as alternatives which could have been uttered. In this paper, I investigate the structure of these alternatives. In principle, alternatives could be analyzed as pure meanings, independent of linguistic form. In contrast, alternatives could be analyzed like actual utterances, constrained by the same grammatical

* With thanks to Geraldine Baniqued, Johann Carlos Sulit Barcena, Luvee Hazel Calventas-Aquino, Jo Castro, Valerie Gamao, Ginalyn Garcia, Anne Jelai, Fely Morallo, and Catherine Tadina for their time and generosity as consultants. Thanks to Cleo Condoravdi, Christopher Potts, Paul Kiparsky, Ivano Caponigro, Dylan Bumford, Lelia Glass, Vera Gribanova, Masoud Jasbi, Sven Lauer, Beth Levin, audiences at UC Berkeley Syntax-Semantics Circle, BLS 42, Stanford, SALT 26, and six anonymous reviewers for SALT 26.

(C)2016 Collins 
Reasoning about definiteness in a language without articles

requirements. I argue for the latter view: in order to derive certain implicatures, alternatives should be analyzed as fully compositional structures appropriately generated by the grammar. Reasoning about what a speaker could have uttered involves reasoning about appropriate actions the speaker could have taken in a given discourse context. Thus it is intuitive that alternatives are required to meet all linguistic conditions met by actual utterances.

The focus of this paper is the so-called 'non-uniqueness' implication of indefinite noun phrases. For example, the English sentence (1), containing an indefinite, implies that the discourse context is compatible with the existence of multiple moons. This contrasts with (2), containing a definite, which is restricted to contexts with a unique salient moon.

(1) Karlos discovered a moon.

(2) Karlos discovered the moon. $\rightsquigarrow$ There is more than one moon

$\rightsquigarrow$ There is only one moon

Several accounts of this pattern (e.g., Hawkins 1991; Heim 1991) claim that the implication in (1) is a conversational implicature derived via competition between the indefinite and definite. Many of these accounts (e.g., Heim 1991; Grønn \& Sæb $\varnothing$ 2012; Horn \& Abbott 2013) assume that pairs of alternative utterances like (1-2) are generated by conventionalized scales of lexical alternatives, in this case, a scale consisting of the articles $a$ and the.

From a cross-linguistic perspective, many languages lack articles like $a$ and the, but are nevertheless able to signal definiteness via other morphosyntactic mechanisms. I ask here how these languages fit into our understanding of pragmatic competition between definites and indefinites. I pose this question in relation to Tagalog, a language which does not express definiteness and indefiniteness with dedicated articles, but with a system of verbal affixes and case marking.

In Section 2 of this paper, I provide evidence that the inference patterns observed with the English examples (1-2) arise with analogous Tagalog examples, such as (3-4). In light of this finding, I ask how we incorporate data from languages without articles, like Tagalog, into our theories of pragmatic competition. ${ }^{1}$

Naka-diskubre si Karlos ng buwan AV-discover NOM Karlos GEN moon

Karlos discovered a moon.

$\rightsquigarrow$ There is more than one moon

Na-diskubre ni Karlos ang buwan

PV-discover GEN Karlos NOM moon

Karlos discovered the moon.

$\rightsquigarrow$ There is only one moon

1 Abbreviations: AV: actor voice; GEN: genitive; LK: linker; NOM: nominative; OBL: oblique; PERF: perfect; PL: plural; PV: patient voice; SG: singular; TOP: topic marker 
In Sections 3-4, I suggest that the Tagalog data can be given the same kind of analysis as the English data, provided we fix some particular assumptions about the nature of alternatives and pragmatic competition. Previous accounts of competition between definites and indefinites invoke the pragmatic principle Maximize Presupposition (following Heim 1991), which stipulates that interlocutors prefer expressions with stronger presuppositions, all else being equal. Certain versions of this account (e.g., Percus 2006; Lauer 2016) take Maximize Presupposition to be a preference between lexical items. With respect to the English data, interlocutors prefer expressions with the presupposition trigger the over the non-presuppositional $a$, thereby generating the observed implicatures.

This account does not extend so neatly to the Tagalog data. I present evidence in Section 4 that no morpheme contained within the expression (4) can be analyzed as triggering the uniqueness presupposition associated with definiteness. Therefore, there is no evidence that the observed inferences in (3-4) are derived via a preference for a presuppositional lexical item (like a definite article) over a non-presuppositional lexical item (like an indefinite article). I claim instead that the inferences are derived from preferences between syntactic structures. In line with the accounts of Singh 2011 and Schlenker 2012, I argue that Maximize Presupposition should be analyzed as a preference adjudicating between clausal-level constituents.

The perspective of this paper is that the syntactic structure of pragmatic alternatives must be taken into account when calculating implicatures. In Section 5, I support this perspective by demonstrating that the non-uniqueness implicature observed in (3) is sensitive to the broader syntactic structure of its containing clause. I show that the non-uniqueness implicature only arises in clause-types in which the verb forms in (3) and (4) are both possible. It is only in such environments that interlocutors can sensibly reason about why the speaker chose one form over the other. In verb-initial sentences, both verb forms are possible, and as such, the non-uniqueness implicature arises. However, in sentences in which the NP denoting the thematic actor is clause-initial, no such alternation is possible: the verb form in (4) is morphosyntactically blocked. Therefore, interlocutors are prevented from reasoning about why one verb form was chosen over the other, and no implicature arises. These data provide evidence that only grammatically well-formed structures are able to enter into pragmatic competition.

In sum, using evidence from Tagalog, a language without articles, this paper sheds light on how interlocutors reason about alternative utterances. Reasoning about what a speaker could have said involves reasoning about utterances which are syntactically complex and appropriately constrained by the grammatical conditions of the language. 
Reasoning about definiteness in a language without articles

\section{Definiteness, case, and voice}

This section provides evidence that definite and indefinite morphosyntactic forms in Tagalog give rise to the same kinds of inferences as the English examples in (1-2), including the non-uniqueness implicature, without the use of articles, focusing on the interpretations of bare NPs which are the thematic patients of transitive verbs. I then go on to show how definite and indefinite interpretations of NPs arise compositionally, following the analysis of Collins 2016a. The definite and indefinite interpretations of bare NPs crucially depend on the voice affix on the transitive verb.

In Tagalog, voice morphemes on verbs are associated with a thematic role. This thematic role will match the thematic role of the NP marked with nominative case. In this paper, I focus on actor voice and patient voice, where the NP marked with nominative case takes the actor role and patient role, respectively. In (5), the verb takes the prefix nag-, signalling actor voice. The actor NP, a first person pronoun, appears in its nominative case form. In (6), the patient NP takes nominative case, signalled by the case marker ang. Argumental NPs which do not correspond to the thematic role of the voice morpheme take genitive case. Genitive case on common nouns is signalled by the case marker $n g$ (pronounced $n a n g$ ). ${ }^{2}$

(5) Nag-tago ako ng kompyuter. AV-hide NOM.1SG GEN computer

'I hid a computer.'

$\mathrm{T}\langle$ in $>$ ago ko ang kompyuter. $\langle\mathrm{PV}\rangle$.hide GEN.1SG NOM computer

'I hid the computer.'

Bare NP patients marked with genitive case, such as $n g$ kompyuter in (5), are interpreted as narrow scope indefinites. Bare NP nominative patients, such as ang kompyuter in (6), are interpreted as definites. Evidence for these characterizations is provided in Sections 2.1-2.2. For additional discussion see Collins 2016a, Collins 2016b, and Paul, Cortes \& Milambiling 2016. The correspondence between bare NP interpretation and voice marking is represented in Figure 1.

Like typical definites, bare nominative patients imply that their descriptive content is uniquely instantiated. Like typical indefinites, bare genitive patients often imply their descriptive content is non-uniquely instantiated. In Section 2.1, I argue that uniqueness is conventionally encoded by bare nominative patients as a presupposition, and in Section 2.2, I argue that the non-uniqueness implication of bare genitive patients arises as a conversational implicature.

2 Other voices exist in Tagalog, including locative voice, instrumental voice, and benefactive voice (see Schachter \& Otanes 1982:ch.5). 


\begin{tabular}{lll}
\hline & Case of patient NP & Interpretation of patient NP \\
\hline Patient voice & nominative & definite \\
Actor voice & genitive & indefinite
\end{tabular}

Figure 1 Bare NP interpretation, case, and voice

\subsection{Nominative patients and uniqueness}

Bare nominative patient arguments trigger presuppositions associated with definiteness. Sentences with bare nominative patients require that interlocutors mutually take for granted the unique instantiation of the NP's descriptive content. Consultants were asked to judge the felicity of different bare nominative patients in the context described in (7). Given standard assumptions about the make-up of cars, the descriptive content is understood to be non-uniquely instantiated in (8), but uniquely instantiated in (9). Felicity improves if the context supports the unique instantiation of the nominative patient's descriptive content.

(7) Context: Maria is calling an insurance agent about her car. The insurance agent asks which part of the car is damaged. Maria says: $\{(8) \mid(9)\}$

?Na-sira ko [ang gulong]

PV-damage GEN.1SG NOM tire

I damaged the tire. (Example comment: It's unhelpful, she should answer which part.)

(9) Na-sira ko [ang manibela].

PV-damage GEN.1SG NOM steering.wheel

I damaged the steering wheel. (Example comment: Correct.)

This implication of uniqueness is conventionally encoded. Reinforcing the uniqueness implication leads to redundancy (11). Cancelling the uniqueness implication suggests that the speaker is backtracking or revising a prior commitment (12).

(10) na-kilala ko ang may-akda ng aklat na iyon PV-meet GEN.1SG NOM author GEN book LK that

I met the author of that book

(11) at, siya ang nag-iisang may-akda ng aklat na iyon and, NOM.3SG NOM only author GEN book LK that

and he is the only author of that book. (Comment: you can omit at siya ang nag-iisang may-akda, it sounds redundant.) 
Reasoning about definiteness in a language without articles

(12) at, meron ibang mga may-akda ng aklat na iyon bukod sa kanya and exist other PL author GEN book LK that besides OBL OBL.3SG and there are other authors of that book besides him. (Comment: It sounds like you're saying and as a matter of fact!.)

Therefore, the uniqueness implication of bare nominative patients is required to be a mutual presumption of interlocutors and furthermore, it resists reinforcement and cancellation. This suggests the implication is conventionally encoded as a presupposition. This is expected on an analysis, like the one in this paper, which takes bare nominative patients to be presuppositional definites.

\subsection{Genitive patients and non-uniqueness}

Bare genitive patients often imply that their descriptive content is non-uniquely instantiated, as in (3). This implication can create infelicities in certain contexts. For example, in contexts where it is mutually assumed by interlocutors that the descriptive content of the NP is uniquely instantiated, the use of a bare genitive patient is highly marked. In (13), the use of genitive case with the NP mundo 'earth' leads to a marked, science-fiction like interpretation.

?nag-poprotekta ako [ng mundo]

AV-protect NOM.1SG GEN earth

?I protect an earth. (Comment: Sounds like a galactic being or something.)

The non-uniqueness implication may be cancelled without contradiction or backtracking and may also be reinforced without redundancy (15-16). These tests suggest the implication should be analyzed as a conversational implicature (see Hirschberg 1985 and Levinson 2000).

naka-kilala ako [ng may-akda ng aklat na iyon]

AV-meet NOM.1SG GEN author GEN book LK that

I met an author of that book

(15) at, siya lang ang nag-iisang may-akda and NOM.3SG only NOM only author

in fact, he was the only author.

(16) at meron ibang mga may-akda bukod sa kanya

and exist other PL author besides OBL him

and there were other authors besides him. 


\begin{tabular}{llll}
\hline & Patient case & Patient interpretation & Implications \\
\hline Patient voice & nominative & definite & uniqueness (presupposition) \\
Actor voice & genitive & indefinite & non-uniqueness (implicature)
\end{tabular}

Figure 2 Case, voice, and implications of bare NP patients

Moreover, the emergence of the non-uniqueness implication is highly context dependent, suggesting it is not conventionally encoded. The following examples are judged as not giving rise to a non-uniqueness implication, despite the presence of actor voice morphology and genitive case-marked patients.

naka-kita ako [ng mantsa ng dugo] AV-see NOM.1SG GEN stain GEN blood

I saw a blood stain. ${ }^{3}$

( $\psi \rightarrow$ there are multiple stains)

(18) Isang araw, naka-huli si Hangdangaw [ng malaking isda] one.LK day, AV-catch NOM Hangdangaw GEN large.LK fish

One day, Hangdangaw caught a large fish. ${ }^{4}$ ( $\psi \rightarrow$ there are multiple large fish)

These examples are variants of Heim's (1991) example "Robert caught a 20 ft. catfish", which similarly does not give rise to a non-uniqueness implication. Heim characterizes a class of contexts which prevent non-uniqueness implications of indefinites from emerging. These are contexts in which the descriptive content of the NP is not presupposed to be instantiated by at least one individual (i.e., prior to the utterance, the interlocutors's assumptions are compatible with there being no 20 ft. catfish). The judgments in (17-18) suggest that a similar principle is operative in Tagalog.

We can expand the table in Figure 1 in order to include the observations presented in this section regarding uniqueness and non-uniqueness implications.

Like English, Tagalog grammar provides a way of signalling definite and indefinite interpretations of NPs. However, Tagalog employs voice affixes and case markers instead of articles. Despite the morphosyntactic differences, definites and indefinites give rise to the same kinds of inferences in both languages.

\subsection{Compositional semantics}

In this section I explain how definite and indefinite interpretations of bare NPs in Tagalog arise compositionally. Collins 2016a provides an account of the correspondence between Tagalog NP interpretation and case/voice morphology. Under

3 www.wattpad.com/176142735-minsan-may-isang-tanga-one-shot-minsan-may-isang

4 pinoyfolktales.blogspot.com/2013/01/panitikan-ng-armm.html 
this account, bare NPs (either nominative or genitive) are interpreted as $\langle e, t\rangle$-type properties. Definite readings of bare NPs arise via type-shifting, appealing to the theory of Partee 1986. The application of covert type-shifting operations is triggered by the NP's surrounding syntactic context.

Following much work on the syntax of western Austronesian voice systems (e.g., Guilfoyle, Hung \& Travis 1992; Pearson 2005; Erlewine, Levin \& van Urk 2015), I take nominative patients to be located in a syntactic position distinct to genitive patients. Under these previous accounts, nominative patients occupy a non-thematic position, while genitive patients occupy their VP-internal, thematic position.

In their non-thematic position (identified as Spec,IP in (19)), nominative bare NPs encounter a type-mismatch: the $\langle e, t\rangle$-type property is unable to compose with the rest of the sentence. Collins 2016a proposes that the patient type-shifts via Partee's iota. This means that the patient is interpreted as the one and only individual who instantiates the NP's descriptive content. This dually resolves the type-mismatch (by shifting the patient to an $e$-type expression) and ensures a definite reading of the NP.

(19)

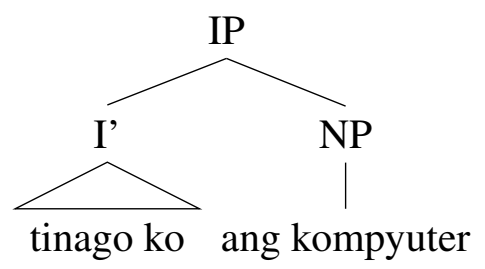

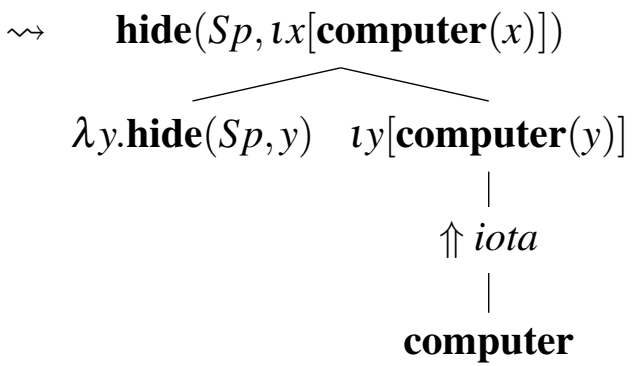

Genitive patients remain in their thematic position as the complement of the verbal root. In Collins 2016a, I propose that the $\langle e, t\rangle$-type patient is existentially quantified by the verbal root itself (compare Van Geenhoven 1998). No type-shifting of the NP takes place. For further details about the compositional analysis, see Collins 2016a.

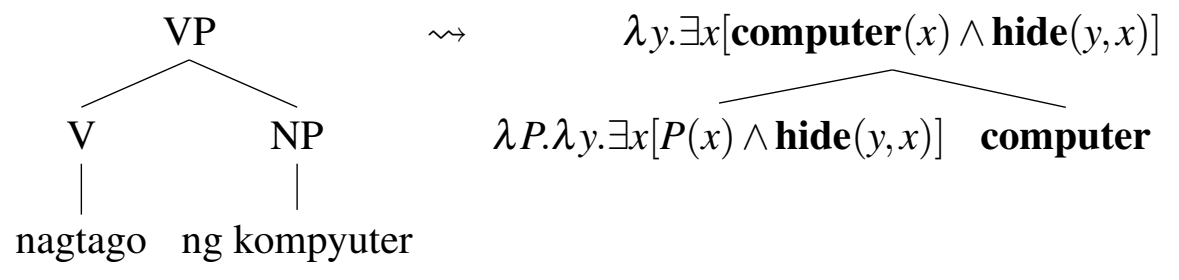

According to this analysis, neither definite bare nominative patients nor indefinite bare genitive patients signal their definiteness or indefiniteness via articles. These effects are derived within the compositional semantics via type-coercion. This account ensures that the uniqueness implication of nominative patients is encoded 
as a presupposition (introduced by iota), while the non-uniqueness implication of genitive patients is not conventionally encoded.

\section{Maximize Presupposition}

This section outlines how the non-uniqueness implicature of indefinites can be derived via the principle Maximize Presupposition (following Heim 1991). In short, Maximize Presupposition refers to a preference for presuppositionally stronger expressions. The theory takes the definite and indefinite variants of a sentence to be alternatives. Semantically, the alternatives differ only by the presence of a presupposition encoded by the definite. Maximize Presupposition therefore determines that the definite should be preferred, so long as its presuppositions are met. Assuming a speaker is obeying Maximize Presupposition, the use of an indefinite form gives rise to implicatures that the presuppositions of the corresponding definite form are not met, provided certain contextual assumptions hold.

Schlenker (2012:393) provides the following characterization of Maximize Presupposition:

\section{Maximize Presupposition}

If a sentence $S$ is a presuppositional alternative of a sentence $S^{\prime}[\ldots]$ and the context $C$ is such that:

i. the presuppositions of $S$ and $S^{\prime}$ are satisfied within $C$;

ii. $S$ and $S^{\prime}$ have the same assertive component relative to $C$;

iii. $S$ carries a stronger presupposition than $S^{\prime}$

then $S$ should be preferred to $S^{\prime}$ (Schlenker 2012:393)

(21) takes the notion of "alternative" to be given: the indefinite and definite variants of a sentence are pre-selected as alternatives to be compared according to this principle. For example, the pair of sentences (22) and (23) should compete via this principle. According to the semantics provided in (22) and (23), the alternatives have the same assertive content. However, the definite (23) carries a presupposition which (22) does not. The presupposition of (23) is represented using the presupposition operator $\partial$ as defined by Beaver $\&$ Krahmer $2001 .^{5}$

$5 \llbracket \partial(\phi) \rrbracket=T$ just in case $\llbracket \phi \rrbracket=T$, otherwise $\llbracket \partial(\phi) \rrbracket=\#$ (i.e., neither true nor false). Adopting a weak Kleene semantics for $\wedge$, a conjunction $[\phi \wedge \psi]$ denotes \# if one of its conjuncts denotes \#. Thus we can express a proposition $\llbracket \phi \rrbracket$ with a presupposition $\llbracket \psi \rrbracket$ as $\llbracket \partial(\psi) \wedge \phi \rrbracket$. If the presupposition of (23) is false (i.e., there are zero or more than one moons), (23) is neither true nor false.

An inadequacy of the weak Kleene semantics for connectives is that they do not adequately characterize the filtering behaviors of natural language connectives like English and (Karttunen 
Reasoning about definiteness in a language without articles

(22) Karlos discovered a moon

$\rightsquigarrow \exists y[\operatorname{moon}(y) \wedge \operatorname{discover}(y)(k)]$

(23) Karlos discovered the moon.

$$
\rightsquigarrow \partial(\exists ! x[\operatorname{moon}(x)]) \wedge \exists y[\operatorname{moon}(y) \wedge \operatorname{discover}(y)(k)]^{6}
$$

Maximize Presupposition, according to the definition (21), determines that (23) should be preferred to (22). Assuming a speaker is obeying Maximize Presupposition, an utterance of the indefinite (22) is less preferred. Interlocutors conclude that the speaker opted for the indefinite alternative as s/he takes the presupposition of the definite alternative (23) to be false (under the assumption of the speaker's epistemic authority). By this reasoning, (22) is strengthened to (24). Here, the property moon is interpreted as being non-uniquely instantiated.

Karlos discovered a moon

$$
\rightsquigarrow[\neg \exists ! x[\operatorname{moon}(x)]] \wedge \exists y[\operatorname{moon}(y) \wedge \operatorname{discover}(y)(k)]
$$

(21i) states that the alternatives are only compared in contexts in which their presuppositions are satisfied, following Heim's original intuition. For example, if interlocutors are not committed to the existence of an individual instantiating the definite's descriptive content, the presupposition of the definite is not satisfied. In such contexts, condition (21i) fails to be met and reasoning via Maximize Presupposition does not take place, blocking the emergence of an implicature.

For example, compare (22) with "Karlos discovered a moon orbiting Mercury", which intuitively does not imply that there are multiple moons orbiting Mercury. Given standard assumptions about the solar system, an utterance of the definite alternative "Karlos discovered the moon orbiting Mercury" would suffer from a presupposition failure. Therefore the condition (21i) is not met, and reasoning via Maximize Presupposition does not apply, blocking the non-uniqueness implicature.

Maximize Presupposition promises to explain the Tagalog data observed in Section 2.2. Taking the actor voice and patient voice variants of a sentence as alternatives, interlocutors will systematically reason about why one verb form was chosen over the other. The actor voice sentence (25), repeating example (14), implicates non-uniqueness via competition with its patient voice alternative (26). As (26) has a definite interpretation, it is preferred according to Maximize Presupposition. Interlocutors therefore reason about why the less preferred (25) was chosen and conclude the uniqueness presupposition of (26) is false.

1973; Beaver \& Krahmer 2001). A more complete analysis would distinguish the $\wedge$ conjoining propositions with their definedness conditions, and the $\wedge$ employed in the translations of natural language conjunction.

6 The meaning of the definite is presented in this format for ease of comparison with the indefinite. The generalized quantifier $\lambda P . \partial(\exists ! x[\operatorname{moon}(x)]) \wedge \exists y[\operatorname{moon}(y) \wedge P(y)]$ is derivable from the $e$-type meaning of the definite in (19) via Partee's lift operator. 
naka-kilala ako [ng may-akda ng aklat na iyon] AV-meet NOM.1SG GEN author GEN book LK that

I met an author of that book $\rightsquigarrow$ There are multiple authors.

na-kilala ko [ang may-akda ng aklat na iyon] PV-meet GEN.1SG NOM author GEN book LK that

I met the author of that book. $\rightsquigarrow$ There is only one author.

Maximize Presupposition also provides an explanation of why (27), repeating earlier example (18), fails to generate a non-uniqueness implicature. Assuming (27) is uttered in a context in which interlocutors do not take the existence of large fish for granted, the patient voice variant with a definite patient triggers a presupposition failure. The alternative therefore do not compete, since (21i) fails.

Isang araw, naka-huli si Hangdangaw [ng malaking isda] one.LK day, AV-catch NOM Hangdangaw GEN large.LK fish

One day, Hangdangaw caught a large fish. ( $\not$ there are multiple large fish)

(28) Isang araw, na-huli ni Hangdangaw [ang malaking isda] one.LK day, PV-catch GEN Hangdangaw NOM large.LK fish

One day, Hangdangaw caught the large fish.

Maximize Presupposition provides an explanation of how indefinites trigger non-uniqueness implicatures and how such implicatures are sensitive to contextual factors. According to the proposal presented here, English and Tagalog sentences with indefinites are pragmatically enriched via the same basic principles. This presents something of a challenge to theories of pragmatic competition. How can we provide a unified analysis to two languages with such different morphosyntactic strategies for marking definiteness? In the following sections I argue that a unified analysis of English and Tagalog is possible provided some assumptions about the nature of alternatives and pragmatic competition are fixed.

\section{Interactions between implicatures and grammar}

In this section, I explain how pragmatic competition between definites and indefinites operates in a language without articles. In Section 4.1, I discuss how alternatives are generated with reference to scales of lexical alternatives. In languages with articles, such scales intuitively consist of indefinite and definite articles, such as $\langle a, t h e\rangle$. I argue that we can similarly employ lexical scales to generate definite and indefinite alternatives in article-free languages like Tagalog, but only if we suspend the assumption that lexical scales are always ordered by semantic strength (contra Horn 1972). 
Reasoning about definiteness in a language without articles

In order to generate implicatures, interlocutors compare the meanings of alternative expressions. Previous theories differ as to the size of the expression being compared. Do we compare simple lexical items, entire utterances, or something at an intermediate level? Following on from the conclusion of Section 4.1, I argue in Section 4.2 that alternative expressions must be compared at a level which is more syntactically complex than the lexical item (contra Percus 2006 and Lauer 2016).

\subsection{Lexical scales and ordering by strength}

One approach to deriving pragmatic alternatives is to substitute individual lexical items. Starting with Horn 1972, many theories make use of conventionalized scales of lexical items, such as $\langle$ some, all $\rangle$, $\langle$ possible, necessary $\rangle$, and $\langle a$, the $\rangle$. In the words of Horn (2006:16): "the affirmation of any weak or intermediate value will implicate (ceteris paribus) that - for all the speaker knows - the value(s) on its left could not be substituted salva veritate." The approach of this paper is to preserve the assumption that scales are employed in generating alternatives. See Katzir 2007 for an approach which avoids the use of scales entirely.

Several theories, including Horn's (1972) original proposal, require items on a lexical scale to be ordered by semantic strength. This approach may be extended to $a$ and the. Both items can be given interpretations which make their ordering by semantic strength obvious, as in (29-30).

$$
\begin{aligned}
& a \rightsquigarrow \lambda P . \lambda Q . \exists x[P(x) \wedge Q(x)] \\
& \text { the } \rightsquigarrow \lambda P . \lambda Q . \partial(\exists ! y[P(y)]) \wedge \exists x[P(x) \wedge Q(x)]
\end{aligned}
$$

However, choosing such a lexical scale in order to generate the Tagalog alternatives is not so simple. Following the analysis in Section 2.3, there is no individual morpheme within a patient voice sentence which encodes for the observed definiteness presupposition. According to this paper's analysis, the definiteness associated with patient voice sentences arises via type-shifting within the semantic composition.

Supporting evidence for this conclusion comes from patient voice sentences in which the nominative patient contains a quantificational determiner. Compare (31), with a bare nominative patient, and (32), with an indefinite nominative patient, containing the indefinite quantificational determiner isang 'one' (see Collins 2016a and Paul et al. 2016 for more details). This data point raises a problem for any analysis which takes the definiteness presupposition of (31) to be introduced by a particular morpheme: every morpheme in the presuppositional (31) is present in the non-presuppositional (32). ${ }^{7}$

7 Collins 2016a provides the following account of (32): isang NP 'one NP' in (32) is a nonpresuppositional generalized quantifier. It composes with its predicate without type-shifting via iota. 
T/in $\rangle$ ago ko ang kompyuter. $\langle\mathrm{PV}\rangle$.hide GEN.1SG NOM computer

'I hid the computer.'
$\mathrm{T}\langle$ in $\rangle$ ago ko
ang isang kompyuter $\langle\mathrm{PV}\rangle$.hide GEN.1SG NOM one computer
I hid a computer.

Preserving the assumption of lexical scales, I propose here that it is the verbal affixes which are conventionalized as lexical alternatives. The lexical scale involved in generating non-uniqueness implicatures consists of the actor voice morpheme and the patient voice morpheme: $\langle\mathrm{AV}, \mathrm{PV}\rangle$. As the patient voice morpheme cannot be said to introduce the definiteness presupposition, there is no sense in which the two voice morphemes are ordered via semantic strength in the same way as $\langle a, t h e\rangle$. Therefore, in order to accept $\langle\mathrm{AV}, \mathrm{PV}\rangle$ as a valid scale of lexical alternatives, we must suspend the requirement that such scales must be ordered by semantic strength.

Previous accounts have noted the shortcomings of the theory that scales must be ordered by semantic strength, including Horn 1972. Hirschberg (1985:ch.5) argues that lexical alternatives may be partially ordered by a host of relations including but not limited to entailment. The approach taken here, as far as the the scale $\langle\mathrm{AV}, \mathrm{PV}\rangle$ is concerned, is somewhat intermediate. The scale $\langle\mathrm{AV}, \mathrm{PV}\rangle$ is not itself ordered by entailment, but given certain structural conditions, fully composed sentence structures containing these voice morphemes may be ordered by entailment in the same way as the English alternatives with $a$ and the.

\subsection{Preferences between expressions}

Theories of implicature calculation via Maximize Presupposition require expressions to be compared relative to their semantic strength. But theories differ as to the level at which relative semantic strength is calculated: at the lexical level, sentential level, or an intermediate level. Here I show how the Tagalog data bear on this debate.

The theory outlined in Percus 2006 assumes that the relative semantic strength should be determined at the level of the lexical item. According to Percus, comparing

Therefore, no presupposition is introduced.

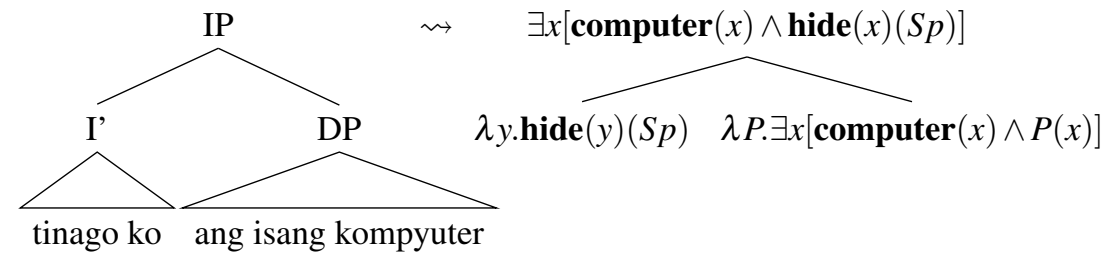


Reasoning about definiteness in a language without articles

fully composed sentences will lead us to miss observed applications of Maximize Presupposition. Percus provides examples like the following pair.

(33) Everyone with exactly two students passed both of his students.

(34) \#Everyone with exactly two students passed all of his students.

If we were to compare the relative semantic strength of (33) and (34) at the level of the entire sentence, (33) would not be presuppositionally stronger than (34). The presupposition introduced by both in (33) is filtered by the universal quantifier subject. Therefore, according to the definition in (21) of Maximize Presupposition, (33) should be no more preferable than (34), leaving the infelicity of (34) unexplained.

Percus proposes that we only need to compare the relative semantic strength of the individual lexical items, here both and all. As both is presuppositionally stronger than all, it should be preferred. Therefore, any sentence containing both should be preferred to its alternative derived by substituting both for all (provided the presuppositions of both alternatives are met).

Percus proposes a revision to the formulation of Maximize Presupposition which can be construed as the following: given a lexical scale $\langle\alpha, \beta\rangle$, a sentence $S$ containing the presuppositionally stronger lexical item $\alpha$ is always preferred to the alternative sentence $S^{\prime}$ containing the lexical item $\beta$, so long as $S$ and $S^{\prime}$ are contextually equivalent. According to this definition, it is irrelevant whether or not the sentence as a whole inherits the presupposition encoded by the individual lexical item. As (33) contains the presuppositionally stronger lexical item, the sentence as a whole should be preferred, even though the presupposition of both ends up not being inherited by the sentence as a whole. An utterance of (34) is therefore understood as violating Maximize Presupposition, creating infelicity.

Singh 2011 argues against this approach of comparing the relative semantics of lexical items on conceptual grounds. ${ }^{8}$

(35) "I know of no other principles of semantics/pragmatics that display preferences among LFs that are sensitive not to their semantic or contextual meanings but rather solely to the lexical items contained within them." (Singh 2011:p156). ${ }^{9}$

8 Singh (2011:Section 3.2) and Schlenker (2012:Sections 3.2.1-2) raise some additional empirical arguments against comparing the semantic strength of lexical items without comparing the semantic strength of larger structures.

9 A response to Singh's concern could be that various manner-based implicatures involve solely the comparison of lexical items. For example, Horn 1984 states that the use of a marked expression as opposed to an unmarked expression (where markedness corresponds to complexity and/or prolixity) invites an inference that the speaker intended to convey a marked message. See also Bergen, Levy \& Goodman 2016 who show how semantically equivalent messages which differ solely in terms of utterance cost can reproduce the kinds of implicatures Horn describes. Lauer 2016 presents a version of Maximize Presupposition which makes explicit comparison to manner based implicatures. 
Singh proposes that the comparison of presuppositional strength is at a level above the lexical item, contra Percus. He proposes that presuppositional strength is checked relative to a sentence's local context. Therefore, a presupposition trigger's context of evaluation may change depending on where the trigger is located within a complex sentence.

Adopting the CCP framework of Heim 1983, Singh analyzes the quantified sentences in (33-34) as in (36-37).

(36) Every $x, x$ has exactly two students, [ $x$ passed both of $x$ 's students]

Every $x, x$ has exactly two student, $[x$ passed all of $x$ 's students]

Under the local version of Maximize Presupposition, the bracketed constituents are compared relative to their local contexts. According to the CCP framework, in order to check whether the presuppositions of the bracketed constituents hold, we check them relative to a context which entails the restrictor of every, i.e., a context which ensures that the individual mapped to $x$ has exactly two students (see Heim 1983:Section 3.2 for technical details). In this local context, the bracketed constituent in (36) with both is presuppositionally stronger than the bracketed constituent in (37) with all. Therefore, it should be preferred via Maximize Presupposition.

The Tagalog data help us decide between approaches which compare the relative strength of lexical items, such as Percus', and approaches which compare the relative strength of complex expression relative to their local contexts, such as Singh's. The data here favor the latter approach.

As argued earlier in the paper, the definiteness of an NP in Tagalog is not encoded by a single lexical item, as evidenced by pairs like (31-32), repeated in (38-39). As every morpheme contained in the definite (38) is contained within the indefinite (39), no particular morpheme in (38) can be said to encode for its definiteness.

$$
\mathrm{T}\langle\text { in }\rangle \text { ago ko ang kompyuter. }
$$
$\langle\mathrm{PV}\rangle$.hide GEN.1SG NOM computer

'I hid the computer.'

$\mathrm{T}\langle$ in $\rangle$ ago ko ang isang kompyuter $\langle\mathrm{PV}\rangle$.hide $1 \mathrm{SG}$ NOM one computer

I hid a computer.

This observation creates problems for any theory which requires that relative presuppositional strength is checked only at the level of the lexical item. In Tagalog, the definiteness of an NP is determined by the broader syntactic structure. Thus, in order to compare the definite (38) with its indefinite alternative (40), we must compare syntactically complex structures. The type-shifting operations responsible for definiteness may only take place at these super-lexical levels. 
Reasoning about definiteness in a language without articles

Nag-tago ako ng kompyuter.

AV-hide NOM.1SG GEN computer

'I hid a computer.'

Therefore, the Tagalog data favor analyses such as Singh's which require that relative semantic strength of alternatives is compared at a level which is syntactically complex enough for type-shifting operations to take place.

\section{Grammatical alternatives}

So far, this paper has argued for a view of implicatures which takes pragmatic alternatives to be syntactically complex expressions. In support of this view, I argue in this section that alternatives should be analyzed as having grammatical structure. In particular, alternatives must be appropriately licensed by the morphosyntactic rules of the language. Certain utterances fail to give rise to implicatures precisely because their alternatives would not be grammatically well-formed.

The non-uniqueness implicatures discussed in this paper only arise in verb-initial sentences. In actor-initial sentences, sentences where the actor NP has moved to a pre-verbal position, the non-uniqueness implicature does not arise. For example, (41) is compatible with a definite interpretation, despite the actor voice affix and genitive case on the patient. The indefinite interpretation is still possible, given the right supporting context.

$\left[\right.$ sino $\left._{i}\right] \quad[$ ang naka-diskubre __ $i$ ng buwan $]$ NOM.who NOM AV-discover GEN moon

Who discovered the/a moon?

Verb-initial actor voice sentences with genitive patients that are infelicitous, such as (42), become felicitous if the actor NP is moved leftward, as in (43).

\#sumukat [ako] $]_{\text {Actor }}[\mathrm{ng}$ kabilugan ng ulo ni John] AV.measure NOM.1SG GEN circumference GEN head GEN John

I measured a circumference of John's head.

$$
\begin{aligned}
& {[\mathbf{a k o}]_{\text {Actor }} \text { ay sumukat [ng kabilugan ng ulo ni John] }} \\
& \text { NOM.1SG TOP AV.measure GEN circumference GEN head GEN John }
\end{aligned}
$$

I'm the one that measured the circumference of John's head.

The effect is consistent across a range of actor-initial clause types (such as clefts, wh-questions, topicalization, and relativization); see McFarland 1978, Schachter \& Otanes 1982, and Rackowski 2002 for examples and discussion. 
I claim that this "disappearing non-uniqueness" effect is due to what is often referred to as the western Austronesian 'Extraction Restriction' (see Schachter 1977, Keenan 1976, and many others). This restriction is roughly paraphrased in (44)

(44) Extraction Restriction: extraction operations only target nominative NPs.

Based on this restriction, the corresponding patient voice version of the actorinitial (43), where the extracted NP is genitive, is ungrammatical.

*[ko] $]_{\text {Actor }}$ ay sinukat [ang kabilugan ng ulo ni John]

GEN.1SG TOP PV.measure NOM circumference GEN head GEN John

On the view defended here, (43) does not pragmatically compete with its alternative (45), because (45) is ungrammatical. Thus, no pragmatic enrichment takes place. The usual reasoning via Maximize Presupposition does not apply for actor-initial sentences like (43). Therefore, interlocutors do not assume the patient voice variant failed to be uttered because its presuppositions were false. Participants are instead able to conclude that the speaker of (43) uttered the actor voice variant because the patient voice variant is ungrammatical.

Earlier definitions of Maximize Presupposition, such as (21), do not refer to the well-formedness of the competing alternatives. Strictly interpreted, nothing in the definition in (21) prevents the actor-initial sentence (43) from pragmatically competing with its ungrammatical alternative (45). Thus, grammatical well-formedness must be a precondition for pragmatic competition:

Well-formedness principle:

If $F$ and $F^{\prime}$ are pragmatic alternatives, then $F$ and $F^{\prime}$ are grammatically well-formed.

Ill-formed expressions will not compete with well-formed expressions. Pragmatic strengthening will not occur if the pragmatic alternative is blocked by the language's grammar. According to this view of pragmatics, alternatives cannot be characterized purely in terms of their meaning, i.e., as fully interpreted logical forms. Certain implicatures are calculated with reference to the linguistic form of the utterance and its alternatives.

One question arising from this proposal is why actor-initial cleft structures like (43), with genitive patients, do not compete with non-cleft structures like (47), with nominative patients.

$$
\begin{aligned}
& \text { sinukat ko [ang kabilugan ng ulo ni John] } \\
& \text { PV.measure GEN.1SG NOM circumference GEN head GEN John } \\
& \text { I measured the circumference of John's head. }
\end{aligned}
$$


Reasoning about definiteness in a language without articles

If such competition were possible, the indefinite genitive patient in (43) would be pragmatically strengthened with a non-uniqueness implicature, contrary to what we observe. What blocks this competition? According to the theory of alternative generation adopted in this paper, alternatives are generated simply by swapping out one lexical item for its scale-mate. The remaining structure is preserved as much as possible. ${ }^{10}$ Intuitively, interlocutors reason that the speaker intended to signal a particular meaning by choosing the cleft structure. Therefore, as far as the definiteness of the patient NP is concerned, interlocutors should hold the cleft structure constant when reasoning about alternative utterances. The same kind of principle holds for other actor-initial clause-types.

Therefore, assessment of an alternative's viability must involve grammatical information, namely, the alternative's grammatical well-formedness. This constraint stems from the basic intuition that alternatives are utterances which (if uttered) would have been appropriate in the context. Alternatives are required to meet all linguistically relevant conditions, phonological, morphosyntactic, semantic, and pragmatic.

\section{Conclusion}

The calculation of pragmatic alternatives is a central question in research on implicatures. Here, I have presented a number of arguments for a theory which takes alternatives to be compositional structures with morphosyntactic forms. The central data informing this point of view come from the calculation of non-uniqueness implicatures triggered by bare NP indefinites in Tagalog. I argued that the definiteness of a bare NP in Tagalog is determined by its broader syntactic context, and therefore pragmatic competition between indefinite and definite bare NPs must involve competition between syntactically complex structures.

In support of this view, I presented data which suggest that alternatives ruled out by Tagalog morphosyntactic constraints do not enter into pragmatic competition, and thus fail to trigger implicatures. Therefore, I propose that alternatives must be taken to have morphosyntactic properties, in particular, morphosyntactic well-formedness. I advocate for a theory of implicatures which takes the calculation of alternatives to be constrained by the morphosyntax of the interlocutors' language.

\section{References}

Beaver, David \& Emiel Krahmer. 2001. A partial account of presupposition projection. Journal of Logic, Language and Information 10(2). 147-182. doi:10.1023/A:1008371413822.

10 See Collins $2016 \mathrm{~b}$ for a more articulated discussion of the procedure of generating alternatives. 
Bergen, Leon, Roger Levy \& Noah Goodman. 2016. Pragmatic reasoning through semantic inference. Semantics and Pragmatics 9(20). doi:10.3765/sp.9.20.

Collins, James N. 2016a. Composition and definiteness without articles: A case study in Tagalog. To appear in North East Linguistics Society (NELS) 46.

Collins, James N. 2016b. Definiteness and implicature in Tagalog. Berkeley Linguistics Society (BLS) 42. 273-292.

Erlewine, Michael Yoshitaka, Theodore Levin \& Coppe van Urk. 2015. What makes a voice system? On the relationship between voice marking and case. Austronesian Formal Linguistics Association (AFLA) 21. 51-68.

Grønn, Atle \& Kjell Johan Sæbø. 2012. A, the, another: A game of same and different. Journal of Logic, Language and Information 21(1). 75-95. doi:10.1007/s10849-011-9148-7.

Guilfoyle, Eithne, Henrietta Hung \& Lisa Travis. 1992. Spec of IP and Spec of VP: Two subjects in Austronesian languages. Natural Language and Linguistic Theory 10(3). 375-414. doi:10.1007/BF00133368.

Hawkins, John. 1991. On (in)definite articles: Implicatures and (un)grammaticality prediction. Journal of Linguistics 27(2). 405-442. doi:10.1017/S0022226700012731.

Heim, Irene. 1983. On the projection problem for presuppositions. West Coast Conference on Formal Linguistics 2. 114-125.

Heim, Irene. 1991. Artikel und Definitheit. In Arnim Von Stechow \& Dieter Wunderlich (eds.), Semantics: An International Handbook of Contemporary Research, Berlin: De Gruyter.

Hirschberg, Julia L. B. 1985. A theory of scalar implicature. Philadelphia, PA: University of Pennsylvania dissertation.

Horn, Laurence R. 1972. On the semantic properties of logical operators in English. Los Angeles, CA: UCLA dissertation.

Horn, Laurence R. 1984. Toward a new taxonomy for pragmatic inference: Q-based and R-based implicature. In Deborah Schiffrin (ed.), Meaning, form, and use in context: Linguistic applications, 163-192. Washington, DC: Georgetown University Press.

Horn, Laurence R. 2006. Implicature. In Laurence R. Horn \& Gregory Ward (eds.), The Handbook of Pragmatics, 3-28. Malden, MA: Blackwell.

Horn, Laurence R. \& Barbara Abbott. 2013. < the,a >: (in)definiteness and implicature. In William P. Kabasenche, Michael O'Rourke \& Matthew H. Slater (eds.), Reference and referring, 325-255. Cambridge, MA: MIT Press.

Karttunen, Lauri. 1973. Presuppositions of compound sentences. Linguistic Inquiry 4(2). 169-193.

Katzir, Roni. 2007. Structurally-defined alternatives. Linguistics and Philosophy 30(6). 669-690. doi:10.1007/s10988-008-9029-y. 
Reasoning about definiteness in a language without articles

Keenan, Edward L. 1976. Towards a universal definition of "subject". In Charles N Li (ed.), Subject and Topic, New York: Academic Press.

Lauer, Sven. 2016. On the status of 'Maximize Presupposition'. Paper presented at Semantics and Linguistic Theory 26, UT Austin.

Levinson, Stephen C. 2000. Presumptive meanings: The theory of generalized conversational implicature. Cambridge, MA: MIT Press.

McFarland, Curtis D. 1978. Definite objects and subject selection in Philippine languages. Studies in Philippine Linguistics 2(1). 139-182.

Partee, Barbara. 1986. Noun phrase interpretation and type-shifting principles. In Jeroen Groenendijk, Dick de Jongh \& Martin Stokhof (eds.), Studies in Discourse Representation Theory and the Theory of Generalized Quantifiers, 115-143. Dordrecht: Foris.

Paul, Ileana, Key Cortes \& Lareina Milambiling. 2016. Definiteness without D: The case of ang and $n g$ in Tagalog. To appear in the Canadian Journal of Linguistics.

Pearson, Matthew. 2005. The Malagasy subject/topic as an A'-element. Natural Language and Linguistic Theory 23(2). 381-457. doi:10.1007/s11049-0041582-7.

Percus, Orin. 2006. Antipresuppositions. In A. Ueyama (ed.), Theoretical and empirical studies of reference and anaphora, 52-73. Japan Society for the Promotion of Science.

Rackowski, Andrea. 2002. The structure of Tagalog: Specificity, voice, and the distribution of arguments. Cambridge, MA: Massachusetts Institute of Technology dissertation.

Schachter, Paul. 1977. Reference-related and role-related properties of subjects. In P. Cole \& J. M. Saddock (eds.), Syntax and Semantics 8: Grammatical Relations, 279-306. New York: Academic Press.

Schachter, Paul \& Fe T. Otanes. 1982. Tagalog Reference Grammar. Berkeley, CA: University of California Press.

Schlenker, Philippe. 2012. Maximize presupposition and Gricean reasoning. Natural Language Semantics 20(4). 391-429. doi:10.1007/s11050-012-9085-2.

Singh, Raj. 2011. Maximize presupposition! and local contexts. Natural Language Semantics 19(2). 149-168. doi:10.1007/s11050-010-9066-2.

Van Geenhoven, Veerle. 1998. Semantic Incorporation and Indefinite Descriptions. Stanford, CA: CSLI. 
Collins

James N. Collins

Department of Linguistics

Building 460

Stanford University

jamesnc@stanford.edu 